\title{
Cystic fibrosis carrier screening effects on birth prevalence and newborn screening
}

\author{
Carlo Castellani, MD1, Luigi Picci, PhD², Gloria Tridello, MSc¹, Elia Casati, PhD¹, Anna Tamanini, PhD², \\ Lucia Bartoloni, PhD ${ }^{4}$, Maurizio Scarpa, MD², Baroukh M. Assael, MD¹, and the Veneto CF Lab Network
}

Purpose: We evaluated the effects of cystic fibrosis (CF) carrier screening on birth prevalence trends and newborn screening (NBS) efficiency by comparing two Italian regions; carrier screening was performed in one region (eastern region (ER)) and not in the other (western region (WR)).

Methods: Annual births of infants with CF, NBS false-positive results, NBS uncertain diagnoses (borderline sweat chloride (BSC)), carrier tests performed, and carriers detected were monitored during the 1993-2013 period.

Measurements and main results: A total of 259 newborns with CF were detected. In the ER, 150 carrier couples were found. Mean annual percentage of birth prevalence decrease was $9 \%$ per 10,000 $(P=0.002)$ and was greater in the ER $(15 \%, P=0.0008$; WR $1 \%$,
$P=$ ns). The WR estimated birth prevalence was $1 / 3,589$ in 1993 and $1 / 3,870$ in 2013; in the ER it was $1 / 2,730$ in 1993 and $1 / 14,200$ in 2013. The ER birth prevalence correlated inversely with the number of carrier couples $(P=0.0032)$. The ratio between CF cases and NBSpositive results significantly decreased in the ER $(1.6 \%, P=0.0001)$ but not in the WR. The ratio between prevalence of BSC and of CF cases increased in the ER $(P=0.008)$ but not in the WR $(P=0.1)$.

Conclusion: Carrier screening was connected with a decrease in birth prevalence of CF. Poorer NBS performance was observed in the carrier screening area.

Genet Med advance online publication 18 June 2015

Key Words: birth prevalence; carrier screening; carrier testing; cystic fibrosis; newborn screening

\section{INTRODUCTION}

Cystic fibrosis (CF), the most frequent life-shortening autosomal recessive disease in countries with a predominantly Caucasian population, is caused by mutations in the CF transmembrane conductance regulator (CFTR) gene. ${ }^{1}$

Because of the disease's severe clinical manifestations, the heavy burden of daily care, and the shortened life expectancy, carrier testing is routinely offered to relatives of CF patients. The CF carrier test may also be offered to individuals of reproductive age with no family history of CF. This carrier screening strategy has been recommended by the American College of Medical Genetics and Genomics ${ }^{2}$ and by the American College of Obstetricians and Gynecologists, ${ }^{3}$ whereas the European CF Society leaves the decision regarding its establishment up to individual countries. ${ }^{4}$ Although no structured communitywide carrier screening has been implemented by any health jurisdiction, in the United States millions of carrier tests have been performed. ${ }^{5}$ The CF carrier test is also offered to the general population in Israel ${ }^{6}$ and in parts of Australia ${ }^{7}$ and Italy. ${ }^{8}$ CF carrier screening has been found to be connected with a decrease in the annual birth prevalence of the disease in the United Kingdom, the United States, and Italy. ${ }^{8-10}$

Early diagnosis and management has been associated with better lung function and nutrition, as well as with reduced burden and cost of care. ${ }^{11-13}$ To detect infants with CF soon after birth, newborn screening (NBS) has been implemented in most of Europe, North America, and Oceania, ${ }^{14,15}$ and it is considered standard care. ${ }^{16,17}$ NBS-positive neonates undergo sweat chloride measurements to distinguish affected infants and healthy infants with false-positive results. In a subset of these infants, CF can be neither confirmed nor excluded. Several definitions have been suggested for this condition. In the United States it has been called "CFTR-related metabolic syndrome,"18 and in Europe it is sometimes called "equivocal CF diagnosis" or "CF screening-positive inconclusive diagnosis.". ${ }^{19}$ In this article these situations are referred to as "uncertain CF."

The detection of false-positive results and of uncertain CF in infants is generally considered a secondary effect of the NBS system, and NBS programs are designed to minimize their number. ${ }^{15}$ It may be argued that the decrease in birth prevalence of CF associated with CF carrier screening ${ }^{8}$ impairs the outcome of NBS by altering the proportions of CF, uncertain $\mathrm{CF}$, and false-positive cases. ${ }^{20}$

This study was aimed at determining whether a negative correlation between carrier screening and birth prevalence of CF previously shown in northeastern Italy ${ }^{8}$ is confirmed over a longer period, as well as whether it affects NBS practice.

${ }^{1}$ Cystic Fibrosis Center, Azienda Ospedaliera Universitaria Integrata, Verona, Italy; ${ }^{2}$ Department of Pediatrics, University of Padua, Padua, Italy; ${ }^{3} \mathrm{Clinical}$ Chemistry and Hematology Laboratory, Azienda Ospedaliera Universitaria Integrata, Verona, Italy; ${ }^{4}$ ULSS 12 "Veneziana"-Ospedale SS.Giovanni e Paolo-Venezia, Venezia, Italy; Correspondence: Carlo Castellani (carlo.castellani@ospedaleuniverona.it) 


\section{ORIGINAL RESEARCH ARTICLE}

\section{MATERIALS AND METHODS}

Areas undergoing study and NBS and carrier screening procedures

Two administrative regions in northeastern Italy (Veneto and Trentino Alto-Adige) were considered. Data collection involved two subareas: the eastern region (ER) and the western region (WR).

In both regions, $\mathrm{CF}$ in newborns is closely monitored by a long-standing NBS program, whose first tier is immunoreactive trypsinogen (IRT) measurement, followed by mutation analysis and meconium lactase determination in newborns with high IRT. ${ }^{8}$ A single laboratory performs all NBS procedures (except local collection of samples), and IRT cutoffs and mutation panels used for the ER and WR are identical. The number of mutations tested has progressively increased since 1993 and until 2004 (Supplementary Table S3 online). Neonates with increased IRT levels at birth and at least one mutation or high meconium lactase levels are considered NBS-positive and are sweat-tested. Neonates with high IRT at birth, no mutations detected, and normal meconium lactase are resampled by 1 month of age; if IRT is persistently elevated, then they are also considered NBS-positive and are sweat-tested.

In the ER the CF carrier test, although not included among public health screening programs, is proactively offered by many gynecologists and general practitioners to individuals or couples of reproductive age, either preconceptionally or prenatally. This practice started in 1994 and has been steadily increasing ever since. Carrier screening has not been implemented in the WR, where the carrier test is offered only to relatives of CF patients or, more recently, to infertile couples planning assisted reproduction.

\section{Data originating from NBS}

Annual data collected for the 1993-2013 period were as follows.

Annual births of infants with CF. Inclusion criteria were positive NBS and/or meconium ileus plus two sweat chloride measurements $\geq 60 \mathrm{mmol} / \mathrm{l}$. Twenty-one neonates with increased IRT who had not been sweat-tested but carried two CF-causing mutations associated with high sweat chloride values ${ }^{21}$ were also included (Supplementary Table S1 online). Those with NBS false-negative results were excluded from the analysis to avoid a time-related recruitment bias because the number of diagnoses due to symptom manifestation may be higher in remote than in recent years.

Because one of the aims of this study was to assess the potential consequences of carrier screening on NBS performance, infants with meconium ileus, who presumably would have been diagnosed at birth regardless of NBS, were excluded from the analysis of the correlation between birth prevalence trends and numbers of either false-positive results or cases of borderline sweat chloride originating from NBS.
Annual number of NBS false positives. Inclusion criteria were positive NBS and sweat chloride level less than $30 \mathrm{mmol} / \mathrm{l}$.

Annual number of infants with borderline sweat chloride values (BSC infants). Inclusion criteria were positive NBS and sweat chloride level between 30 and $59 \mathrm{mmol} / \mathrm{l}$ (highest of two sweat test results). These infants received an "uncertain CF" diagnosis. The group includes eight children who eventually had CF diagnosed.

\section{Data originating from carrier screening}

An inquiry about molecular laboratories offering CFTR molecular analysis in the ER was carried out through various information channels, including previous publications, ${ }^{8}$ regional archives, and genetic counseling databases. These laboratories were asked to participate in a working group that contributed data and participated in the study design and interpretation of results (Veneto CF Lab Network).

Data were collected for the period January 1993 to December 2013 and included the following: (i) number of carrier tests performed per year, (ii) number of carriers detected per year, (iii) number of carrier couples detected per year, (iv) number of prenatal diagnoses performed per year, and (v) number of affected fetuses diagnosed through prenatal diagnosis per year.

For items (ii), (iii), (iv), and (v), only CF-causing mutations as defined by the CFTR2 project $^{21}$ were considered (22 July 2013 version). It is likely that data from items (iv) and (v) represent an underestimation, as only a few of the laboratories offer molecular analysis for prenatal diagnosis and several carrier couples may have accessed care at other places.

Most, but not all, of the laboratories in the network were the same as those contacted in a previous survey, which explains the slight difference in the two reports. ${ }^{8}$

\section{Statistical analyses}

Descriptive statistics were reported in percentages for categorical variables and as mean, standard deviation, median, and range for continuous variables.

The annual CF birth prevalence was estimated as the ratio between the new CF cases diagnosed by NBS and the total number of newborns tested.

A linear regression model was used to estimate the timerelated variation of CF birth prevalence, the variation of BSC prevalence, the ratio between the prevalence of $\mathrm{BSC}$ and $\mathrm{CF}$ in newborns, the positive predictive value (PPV) (ratio between true positives and the total of true positives and false positives of the NBS system), and the prevalence of false positives. The regression model was also used to calculate the estimated prevalence for each year. In all models, the difference between the $\mathrm{ER}$ and the WR was tested.

To reduce variability, 3-year groups were considered to compute estimated annual birth prevalence. The correlation between the annual birth prevalence of CF cases (meconium ileus excluded) and the numbers of carrier tests, detected carriers, and carrier couples in the ER was analyzed by Pearson 
correlation; confidence intervals were obtained using bootstrap analysis. ${ }^{22}$ The protocol study was approved by the Verona Hospital Ethics Committee (PROG. CE 2394).

\section{RESULTS}

\section{Birth prevalence and carrier screening}

Over the study period, the total number of screened neonates was $1,112,620$ (685,575 in the ER; 427,045 in the WR), with an annual average of 52,982. A total of 259 newborns with CF were detected through NBS and/or because of meconium ileus (145 in the ER, 114 in the WR). Annual distributions in the ER and in the WR are shown in Table 1. Twelve infants with CF (positive sweat chloride test results) were missed by the NBS program, but CF was later revealed by the development of clinical manifestations consistent with CF. The average CF birth prevalence for the period was 1/4,296 (1/4,106 including false-negative results).

A time-related decrease in birth prevalence was confirmed, with a mean annual percentage decrease of 9\% (95\% CI: $4-15 \% ; P=0.002)$. The rate of decrease was greater in the ER (ER: decrease rate, $15 \%$; $95 \%$ CI: 7-23\%; $P=0.0008$; WR: decrease rate; $1 \%$; $95 \%$ CI: -8 to $10 \% ; P=\mathrm{ns}$; ER-WR difference: $-14 \% ; P=0.02$ ) (Figure 1). Estimated birth prevalence in the WR moved from $1 / 3,589$ in 1993 to $1 / 3,870$ in 2013; in the ER it moved from $1 / 2,730$ in 1993 to $1 / 14,200$ in 2013. These estimates were obtained from the following models: ER birth prevalence $=298.4-0.15 \times$ years; WR birth prevalence $=23.0-0.01 \times$ years; and entire-area birth prevalence $=191.4-0.09 \times$ years.

To reduce variability, the analyses were repeated using 3-year cell sizes and the results were confirmed, with the exception of the ER-WR difference, which approached statistical significance $(P=0.053)$ (Supplementary Figure $\mathbf{S 5}$ online).

Mutation analysis data were collected from 16 laboratories in the ER. From 1994 to 2013 174,494 carrier tests were performed; 5,966 carriers and 150 carrier couples were detected. The annual numbers of carrier tests, detected carriers, carrier couples, prenatal diagnoses, and consequently detected affected fetuses are reported in Table 2. Carrier rate (number of carriers/number of tests) was $1 / 29$. Birth prevalence of CF cases in the ER showed a significant negative correlation of -0.69 (bootstrap 95\% CI: -0.84 to -0.50 ) with the number of tests $(P=0.0005)$, a negative correlation of -0.69 (bootstrap 95\% CI: -0.83 to -0.49$)$ with the number of carriers $(P=0.0005)$,

Table 1 Annual distribution of newborns with CF in the ER, the WR, and in the entire study area (CF with meconium ileus included)

\begin{tabular}{|c|c|c|c|c|c|c|c|c|c|c|c|c|}
\hline \multirow[b]{2}{*}{ Year } & \multicolumn{4}{|c|}{ East region } & \multicolumn{4}{|c|}{ West region } & \multicolumn{4}{|c|}{ Total } \\
\hline & Screened & $\mathrm{CF}$ & $\begin{array}{c}\text { Observed } \\
\text { birth } \\
\text { prevalence } \\
\text { (per } 10,000 \\
\text { newborns) } \\
\end{array}$ & $\begin{array}{l}\text { Estimated } \\
\text { birth } \\
\text { prevalence } \\
\text { (per 10,000 } \\
\text { newborns) } \\
\end{array}$ & Screened & $\mathrm{CF}$ & $\begin{array}{c}\text { Observed } \\
\text { birth } \\
\text { prevalence } \\
\text { (per } 10,000 \\
\text { newborns) }\end{array}$ & $\begin{array}{c}\text { Estimated } \\
\text { birth } \\
\text { prevalence } \\
\text { (per 10,000 } \\
\text { newborns) } \\
\end{array}$ & Screened & CF & $\begin{array}{l}\text { Observed } \\
\text { birth } \\
\text { prevalence } \\
\text { (per 10,000 } \\
\text { newborns) }\end{array}$ & $\begin{array}{c}\text { Estimated } \\
\text { birth } \\
\text { prevalence } \\
\text { (per } 10,000 \\
\text { newborns) }\end{array}$ \\
\hline 1993 & 28,852 & 10 & 3.466 & 3.663 & 17,846 & 6 & 3.362 & 2.786 & 46,698 & 16 & 3.426 & 3.322 \\
\hline 1994 & 29,029 & 12 & 4.134 & 3.515 & 17,956 & 5 & 2.785 & 2.776 & 46,985 & 17 & 3.618 & 3.228 \\
\hline 1997 & 30,458 & 4 & 1.313 & 3.070 & 18,839 & 5 & 2.654 & 2.746 & 49,297 & 9 & 1.826 & 2.945 \\
\hline 1998 & 31,126 & 10 & 3.212 & 2.923 & 19,252 & 6 & 3.116 & 2.736 & 50,378 & 16 & 3.176 & 2.851 \\
\hline 1999 & 31,729 & 9 & 2.837 & 2.775 & 19,626 & 8 & 4.077 & 2.726 & 51,355 & 17 & 3.310 & 2.756 \\
\hline 2000 & 31,918 & 9 & 2.820 & 2.627 & 19,742 & 5 & 2.533 & 2.715 & 51,660 & 14 & 2.710 & 2.662 \\
\hline 2001 & 32,939 & 5 & 1.518 & 2.479 & 20,375 & 9 & 4.417 & 2.706 & 53,314 & 14 & 2.626 & 2.567 \\
\hline 2005 & 34,872 & 4 & 1.147 & 1.888 & 21,572 & 3 & 1.391 & 2.665 & 56,444 & 7 & 1.240 & 2.190 \\
\hline 2006 & 35,345 & 3 & 0.849 & 1.739 & 21,766 & 6 & 2.756 & 2.655 & 57,111 & 9 & 1.576 & 2.096 \\
\hline 2007 & 35,630 & 3 & 0.842 & 1.592 & 21,989 & 7 & 3.184 & 2.645 & 57,619 & 10 & 1.736 & 2.001 \\
\hline 2008 & 36,287 & 2 & 0.551 & 1.444 & 22,593 & 5 & 2.213 & 2.634 & 58,880 & 7 & 1.189 & 1.907 \\
\hline 2009 & 35,484 & 5 & 1.409 & 1.296 & 22,093 & 3 & 1.358 & 2.624 & 57,577 & 8 & 1.389 & 1.813 \\
\hline 2010 & 33,479 & 9 & 2.688 & 1.148 & 20,844 & 5 & 2.399 & 2.614 & 54,323 & 14 & 2.577 & 1.718 \\
\hline 2011 & 33,860 & 7 & 2.067 & 1.000 & 21,921 & 6 & 2.737 & 2.604 & 55,781 & 13 & 2.330 & 1.624 \\
\hline 2012 & 33,437 & 4 & 1.196 & 0.852 & 21,383 & 2 & 0.935 & 2.594 & 54,820 & 6 & 1.094 & 1.530 \\
\hline 2013 & 31,194 & 3 & 0.962 & 0.704 & 20,414 & 12 & 5.879 & 2.584 & 51,608 & 15 & 2.906 & 1.435 \\
\hline Total & 68,5575 & 145 & 2.115 & & 42,7045 & 114 & 2.670 & & $11,12,620$ & 259 & 2.328 & \\
\hline
\end{tabular}

For each year, estimated birth prevalence computed by the regression model is reported.

$C F$, cystic fibrosis; ER, eastern region; WR, western region. 


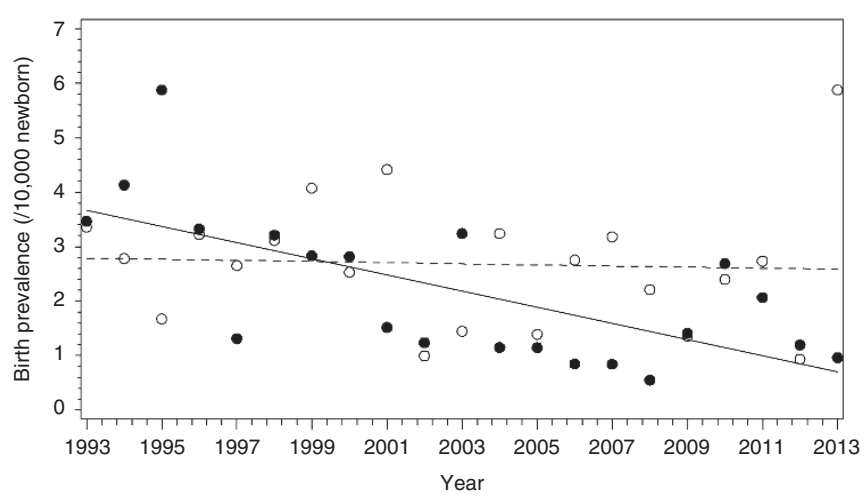

Figure 1 Cystic fibrosis birth prevalence trend in the eastern region (solid line, full dots) and in the western region (dotted line, empty dots).

and a negative correlation of -0.61 (bootstrap $95 \% \mathrm{CI}:-0.79$ to $-0.30)$ with the number of carrier couples $(P=0.0032)$.

\section{NBS false-positives and intermediate sweat chlorides}

A total of 206 neonates had CF diagnosed solely through NBS (no meconium ileus). Data per year for infants with false-positive results and BSC are shown in Table 3.

There were $997(1 / 1,116)$ NBS false-positive results. The birth prevalence of false-positive results increased over time in the entire area (annual increase rate, 32\%; 95\% CI: 11-54\%; $P=0.005$ ) and in the two regions (increase rate, $30 \%$; $95 \% \mathrm{CI}$ : $9-51 \%, P=0.008$ in the ER; increase rate, 36\%; $95 \%$ CI: 8-65\%; $P=0.01$ in the WR) (Supplementary Figure S1 online). The difference between the two slopes was $-6 \%(P=0.7)$. In the entire area, the PPV decreased (decrease rate: $1.3 \%$; $95 \%$ CI: $0.7-2.0 \% ; P=0.0005)$. The rate of decrease was significant in the ER (1.6\%; 95\% CI: 0.9-2.3\%; $P=0.0001$; estimated PPV $35 \%$ in 1993; estimated PPV $3 \%$ in 2013) and was nonsignificant in the WR (estimated PPV $31 \%$ in 1993; estimated PPV 12\% in 2013) (Supplementary Figure S2a,b online). The difference between the two slopes was not significant $(P=0.3)$.

Seventy-nine newborns with BSC were detected through NBS $(1 / 14,084)$. The birth prevalence of newborns with BSC did not change over time significantly in the entire area $(P=0.9)$. There was a significant rate of decrease in the WR (decrease rate, 6\%; 95\% CI: $1-11 ; P=0.02$ ), whereas a nonsignificant increment was observed in the ER (increase rate, $3 \% ; 95 \% \mathrm{CI}:-0.3$ to 7 ; $P=0.07$ ) (Supplementary Figures $\mathbf{S 3}$ and S4 online). The difference between the two slopes was significant $(P=0.003)$. The ratio between the birth prevalence of BSC and CF in newborns increased in the ER (5\%; 95\% CI: $1-8 ; P=0.008)$, whereas a nonsignificant decrease was observed in the WR $(P=0.1)$. The difference between the two slopes was significant $(P=0.003)$ (Figure 2).

\section{DISCUSSION}

This article follows up, expands on, and confirms previous findings of the correlation between carrier screening and decreased birth prevalence of $\mathrm{CF}^{8}$ Moreover, this is the first
Table 2 Annual number of tests, carriers, carrier couples, prenatal diagnoses, and affected fetuses in the eastern region

\begin{tabular}{cccccc}
\hline Year & Tests & Carriers & $\begin{array}{c}\text { Carrier } \\
\text { couples }\end{array}$ & $\begin{array}{c}\text { Prenatal } \\
\text { diagnoses }\end{array}$ & $\begin{array}{c}\text { Affected } \\
\text { fetuses }\end{array}$ \\
\hline 1993 & 0 & 0 & 0 & 0 & 0 \\
\hline 1994 & 25 & 0 & 0 & 0 & 0 \\
\hline 1995 & 681 & 34 & 2 & 0 & 0 \\
\hline 1996 & 1,685 & 76 & 4 & 0 & 0 \\
\hline 1997 & 2,275 & 96 & 6 & 2 & 0 \\
\hline 1998 & 3,200 & 140 & 6 & 1 & 0 \\
\hline 1999 & 3,721 & 159 & 5 & 2 & 0 \\
\hline 2000 & 5,292 & 242 & 10 & 4 & 0 \\
\hline 2001 & 6,447 & 256 & 10 & 2 & 1 \\
\hline 2002 & 7,476 & 282 & 10 & 6 & 4 \\
\hline 2003 & 8,499 & 315 & 11 & 5 & 1 \\
\hline 2004 & 9,474 & 312 & 9 & 4 & 1 \\
\hline 2005 & 10,921 & 364 & 12 & 4 & 0 \\
\hline 2006 & 13,675 & 408 & 10 & 4 & 1 \\
\hline 2007 & 15,653 & 495 & 7 & 3 & 0 \\
\hline 2008 & 17,178 & 529 & 9 & 5 & 3 \\
\hline 2009 & 15,215 & 502 & 11 & 4 & 0 \\
\hline 2010 & 16,048 & 528 & 11 & 12 & 7 \\
\hline 2011 & 15,941 & 541 & 5 & 5 & 3 \\
\hline 2012 & 11,286 & 371 & 6 & 5 & 7 \\
\hline 2013 & 9,802 & 316 & 6 & 3 & 3 \\
\hline Total & 174,494 & 5,966 & 150 & 71 & 31 \\
\hline & & & & & \\
\hline
\end{tabular}

study examining the effects of such birth prevalence reduction on CF NBS.

\section{CF carrier screening and birth prevalence}

Annual births of children with CF tend to fluctuate and, in order to interpret birth prevalence trends, several years need to be examined. An investigation of short periods may be misleading. In the 1983-2006 Colorado records, minor birth prevalence variations were reported; however, when longerterm data were evaluated, no temporal trends could be ascertained. ${ }^{23}$ In Brittany, during 1990-2005, the annual average decrease in birth prevalence was $-0.6 \%$, as opposed to $-1.8 \%$ in $1975-2009 .^{24}$

We have already shown a significant decline of CF birth prevalence over a 15-year timeframe in a northeastern Italian territory where carrier screening is performed (ER), but not in a nearby region where couples with negative family history for CF are not offered the carrier test (WR). ${ }^{8}$ The present study examines a longer period (21 years) and strengthens the previous evidence by confirming a 15\% (95\% CI: 7-23\%) annual birth prevalence decrease in the same carrier screening area (estimated birth prevalence from $1 / 2,730$ to $1 / 14,200$ ) as opposed to a $1 \%(95 \% \mathrm{CI}:-8$ to $10 \%)$ annual decrease in the region where carrier screening was not offered (estimated birth prevalence from $1 / 3,589$ to $1 / 3,870$ ). We also confirm the inverse correlation between births of children with $\mathrm{CF}$ 
Table 3 Annual distribution of false-positive rates and infants with BSC in the ER, the WR, and in the entire study area (CF with meconium ileus excluded)

\begin{tabular}{|c|c|c|c|c|c|c|c|c|c|c|c|c|}
\hline \multirow[b]{2}{*}{ Year } & \multicolumn{4}{|c|}{ East region } & \multicolumn{4}{|c|}{ West region } & \multicolumn{4}{|c|}{ Total } \\
\hline & CF & BSC & $\begin{array}{c}\text { False- } \\
\text { positive }\end{array}$ & PPV & CF & BSC & $\begin{array}{c}\text { False- } \\
\text { positive }\end{array}$ & PPV & $\mathrm{CF}$ & BSC & $\begin{array}{c}\text { False- } \\
\text { positive }\end{array}$ & PPV \\
\hline 1993 & 8 & 1 & 12 & $40 \%$ & 4 & 3 & 6 & $40 \%$ & 12 & 4 & 18 & $40 \%$ \\
\hline 1994 & 11 & 1 & 22 & $33 \%$ & 5 & 4 & 11 & $31 \%$ & 16 & 5 & 33 & $33 \%$ \\
\hline 1995 & 14 & 0 & 17 & $45 \%$ & 2 & 3 & 15 & $12 \%$ & 16 & 3 & 32 & $33 \%$ \\
\hline 1996 & 8 & 2 & 17 & $32 \%$ & 4 & 2 & 18 & $18 \%$ & 12 & 4 & 35 & $26 \%$ \\
\hline 1997 & 4 & 1 & 41 & $9 \%$ & 2 & 2 & 24 & $8 \%$ & 6 & 3 & 65 & $8 \%$ \\
\hline 1998 & 8 & 2 & 21 & $28 \%$ & 6 & 1 & 6 & $50 \%$ & 14 & 3 & 27 & $34 \%$ \\
\hline 1999 & 7 & 2 & 12 & $37 \%$ & 7 & 1 & 9 & $44 \%$ & 14 & 3 & 21 & $40 \%$ \\
\hline 2000 & 8 & 1 & 20 & $29 \%$ & 4 & 4 & 9 & $31 \%$ & 12 & 5 & 29 & $29 \%$ \\
\hline 2001 & 4 & 2 & 21 & $16 \%$ & 8 & 0 & 8 & $50 \%$ & 12 & 2 & 29 & $29 \%$ \\
\hline 2002 & 2 & 2 & 19 & $10 \%$ & 1 & 1 & 17 & $6 \%$ & 3 & 3 & 36 & $8 \%$ \\
\hline 2003 & 9 & 1 & 18 & $33 \%$ & 3 & 0 & 20 & $13 \%$ & 12 & 1 & 38 & $24 \%$ \\
\hline 2004 & 4 & 1 & 32 & $11 \%$ & 5 & 5 & 30 & $14 \%$ & 9 & 6 & 62 & $13 \%$ \\
\hline 2005 & 3 & 5 & 55 & $5 \%$ & 2 & 2 & 29 & $6 \%$ & 5 & 7 & 84 & $6 \%$ \\
\hline 2006 & 2 & 1 & 41 & $5 \%$ & 4 & 1 & 18 & $18 \%$ & 6 & 2 & 59 & $9 \%$ \\
\hline 2007 & 3 & 2 & 34 & $8 \%$ & 5 & 1 & 14 & $26 \%$ & 8 & 3 & 48 & $14 \%$ \\
\hline 2008 & 2 & 2 & 32 & $6 \%$ & 4 & 0 & 23 & $15 \%$ & 6 & 2 & 55 & $10 \%$ \\
\hline 2009 & 4 & 6 & 49 & $8 \%$ & 2 & 1 & 46 & $4 \%$ & 6 & 7 & 95 & $6 \%$ \\
\hline 2010 & 7 & 0 & 33 & $18 \%$ & 5 & 1 & 25 & $17 \%$ & 12 & 1 & 58 & $17 \%$ \\
\hline 2011 & 5 & 7 & 33 & $13 \%$ & 3 & 2 & 26 & $10 \%$ & 8 & 9 & 59 & $12 \%$ \\
\hline 2012 & 3 & 1 & 34 & $8 \%$ & 2 & 2 & 24 & $8 \%$ & 5 & 3 & 58 & $8 \%$ \\
\hline 2013 & 3 & 3 & 36 & $8 \%$ & 9 & 0 & 20 & $31 \%$ & 12 & 3 & 56 & $18 \%$ \\
\hline Total & 119 & 43 & 599 & $17 \%$ & 87 & 36 & 398 & $18 \%$ & 206 & 79 & 997 & $17 \%$ \\
\hline
\end{tabular}

BSC, borderline sweat chloride; CF, cystic fibrosis; ER, eastern region; PPV, positive predictive value; WR, western region.

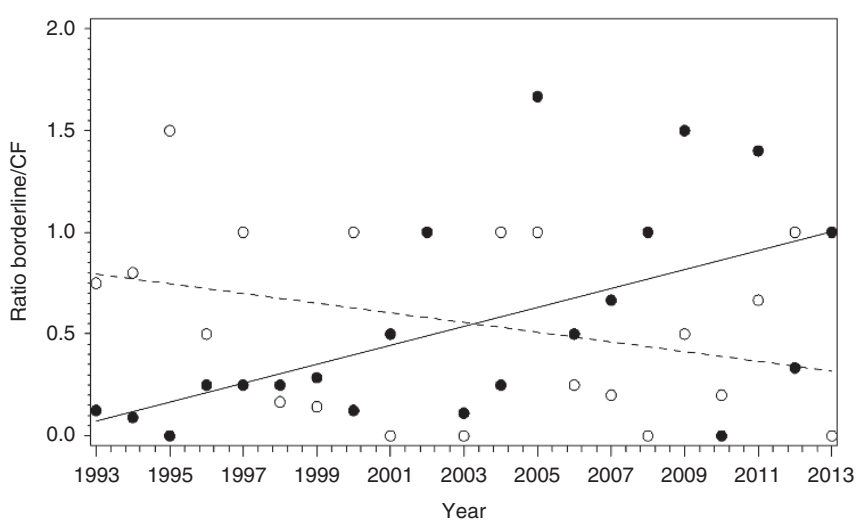

Figure 2 Ratio between the birth prevalence of borderline sweat chloride and cystic fibrosis newborns in the eastern region (solid lines, solid dots) and in the western region (dotted lines, empty dots).

and carrier couples detected by community carrier screening. In addition, we detected a significant negative correlation between birth prevalence of CF and number of carrier tests and of detected carriers. These results substantiate the connection between a negative trend in CF birth prevalence and the extensive offer of carrier tests.

Interestingly, the numbers of tests performed, and consequently of carriers detected, were lower in the past two years. Although the analysis is offered at a low cost, an unfavorable economic situation may have influenced the decision to have the test. If this trend is confirmed, then it will be interesting to see whether birth prevalence will start to increase again in the next years.

The validity of the results is corroborated by the inclusion in the study of unquestionable CF cases only, and by the previously demonstrated homogeneity of the ethnic distribution in the west and in the east. ${ }^{8}$ The good detection rate of the neonatal diagnostic system is emphasized by the small number of false-negative results (5\% of the total diagnoses), although it cannot be excluded that some of them, especially for those born in more recent years, may have not yet been detected. Because of the potential incompleteness of the false-negative data, they were not considered in the analysis because their skewed temporal distribution would have accentuated the downward birth prevalence trend and improperly strengthened our conclusions.

An important limitation of this study is the lack of any direct information regarding the reproductive choices made by the carrier couples. Data retrieval from obstetric termination records was impracticable for privacy reasons. Also, several couples presumably moved to other European countries for assisted reproduction because preimplantation genetic diagnosis and heterologous fertilization were illegal in Italy for most of the study period. Nevertheless, only two of the infants with $\mathrm{CF}$ during the period studied were born from carrier couples detected through carrier screening, which suggests that these 
couples chose not to have affected children. We acknowledge that these choices are not necessarily universal and might have been different in other populations or countries, depending on the accuracy of information received, the perception of disease severity, the availability of preimplantation or prenatal diagnosis, and the general attitude toward pregnancy termination.

\section{Effects of carrier screening on NBS}

The repercussions of population carrier screening on NBS reported in this study are connected with the downward birth prevalence trend.

Carrier screening affects criteria for implementation of NBS. In the later years of the study, CF birth prevalence in the carrier screening area was less than $1 / 10,000$. It may be questioned whether birth prevalence much inferior to the $1 / 2,500-4,000$ reported in most predominantly Caucasian countries ${ }^{25}$ justifies the implementation of NBS. Standards of care guidelines recently produced by the European CF Society state that if the incidence of CF is less than $1 / 7,000$, careful evaluation is required regarding whether NBS is reasonable. ${ }^{17}$ Although this assertion refers more to implementing CF NBS programs than to maintaining those already in place, the question of how desirable it may be to assume the costs and side effects of NBS, such as detection of carriers, false-positive results, and infants with indeterminate diagnosis, in exchange for such relatively small yield is a fair one. Health Technology Assessment studies have generally supported the establishment of CF NBS, ${ }^{11,26}$ but they were performed in populations with or using models with higher birth prevalence. New cost-benefit analyses may be necessary to determine the validity of CF NBS in a low-birth prevalence context.

Carrier screening and the PPV of NBS. Most NBS programs include mutation analysis as a second tier in IRT-positive newborns, which entails a variable number of infants with false-positive results being carriers. Although the detection of a carrier newborn may originate potentially useful cascade genetic testing in the family, a low number of false-positive results is usually considered a marker of good quality in any CF NBS protocol. Carrier screening is not expected to be associated with a decrease in NBS false-positive results because their number depends on factors other than birth prevalence of disease, such as the setting of the IRT cutoffs and, whether mutation analysis is included in the protocol, the frequency of carriers in the screened population, and the sensitivity of the mutation panel. ${ }^{20}$ This was confirmed by the study results that showed an increase in the number of false-positive results detected by NBS both in the ER and in the WR, a change probably connected with the gradual expansion of the mutation panel used by the NBS protocol.

It is controversial whether carrier screening had an effect on NBS PPV. In the ER, the combined effect of the increase of false-positive results and, to a lesser extent, of the decrease of true-positive results resulted in less efficient performance of the
NBS system, represented by the significant decrease of its PPV. PPV decreased in the WR as well, although not significantly, and the difference between the ER and WR slopes was not significant either. A low PPV is a widely acknowledged drawback of CF; the European CF Society recommends a minimum PPV of $0.3 .{ }^{17}$ Monitoring these trends for a longer period or in larger populations may help to confirm whether carrier screening affects NBS PPV.

Carrier screening and the CFluncertain CF ratio. NBS is designed to detect infants with $\mathrm{CF}$ during an early stage, thus contributing to optimizing their chances of limiting a severe and life-shortening disease. ${ }^{15}$ Whether children with inconclusive diagnoses uncovered by NBS may benefit from being identified is still considered a moot point. Although a subset of these infants may, over time, acquire a clinical phenotype consistent with CF, many others are expected to experience evolution of minor disorders connected with $\mathrm{CFTR}^{27}$ or to never have any significant symptoms. ${ }^{18}$ Most of our children with BSC are followed up at the CF Centre, and eight of them eventually had CF diagnosed on the grounds of repeatedly positive sweat chloride values, but so far none of them has shown any major manifestation of lung disease.

Uncertain CF cases are distinguished by genotypes where at least one mutation does not cause $\mathrm{CF}^{18,19}$ Some mutations of unclear clinical liability are included in panels used for carrier screening (Supplementary Table S2 online), and some carriers of them may be detected. However, given the milder clinical phenotype usually associated with these mutations and the absence of a clear CF-causing label, their detection is not expected to have consequences on parents' reproductive decisions, and carrier screening is not anticipated to have effects on the birth prevalence of uncertain CF cases detected by NBS. ${ }^{20}$ This study confirms this assumption, because the birth prevalence of newborns with BSC did not significantly change in the ER.

In the same area, the ratio between $\mathrm{CF}$ and uncertain $\mathrm{CF}$ has changed, and the number of uncertain CF cases detected by NBS is now close to that of new CF cases, an event that did not occur in the WR. This change is connected with the decreasing numbers of newborns with CF produced by carrier screening. However, the contemporary decline of children with BSC in the WR makes it difficult to interpret this phenomenon. Again, longer observations of these trends may prove useful to understand them better (Supplementary Table S4).

It is also worth mentioning that the number of uncertain diagnoses identified by NBS was higher than that reported because the mutation panel used in the NBS protocol included a few mutations not acknowledged as CF-causing. ${ }^{21}$ Twenty-two infants with negative sweat tests but two mutations-of which at least one was not clearly connected with CF-were identified. These infants received an uncertain CF diagnosis but, to avoid a temporal bias, they were not included in the study because in the 1990s the mutations of unclear clinical impact, like R117H, were not included in the NBS mutation panel (Supplementary Table S3 online). 
This study determined that, over a long period of time, population carrier screening is connected with a significant decrease in CF birth prevalence. Conversely, carrier screening did not affect the number of false-positive results or of uncertain diagnoses originating from NBS. The combination of these two circumstances may possibly affect NBS efficiency.

Similar results may not necessarily be found in other areas and populations, but if confirmed they should be taken into consideration in the planning of CF screening policies.

\section{SUPPLEMENTARY MATERIAL}

Supplementary material is linked to the online version of the paper at http://www.nature.com/gim

\section{ACKNOWLEDGMENTS}

This study was supported by grant 8/2011 from the Italian CF Foundation and a grant from the Italian Ministry of Health-CCM, Agenzia Nazionale per I Servizi Sanitari Regionali, Cod. CUP 185J12001480001. Some of the results in this paper were presented in abstract form at the 28th Annual North American Cystic Fibrosis Conference and published in Pediatric Pulmonology, 49(S38):S1-S86, September 2014.

The members of the Veneto CF Lab Network are Albertin M., Casa di Cura Abano Terme-Abano Terme; Bonfante A., ULSS 3-Ospedale di Bassano-Bassano del Grappa; Boni S., ULSS 1-Ospedale di Belluno-Belluno; Businaro V., RDI (Rete Diagnostica Italiana)Limena; Cardarelli L., Citotest-Sarmeola di Rubano; Delle Carbonare M., Research \& Innovation-Padova; Dulcetti F., Toma Advanced Biomedical Assays-Busto Arsizio; Egiziano S., ULSS 12 "Veneziana"-Ospedale SS.Giovanni e Paolo-Venezia; Fabris M, Research \& Innovation-Padova; Guercini N., ULSS 6 VicenzaOspedale di Vicenza-Vicenza; Hladnik U., Fondazione Malattie Rare "Mauro Baschirotto"-Costozza di Longare; La Grasta G., Research \& Innovation-Padova; Lapucci C., Genetic Lab-Noventa Vicentina; Leon A., Research \& Innovation-Padova; Lippi E., RDI (Rete Diagnostica Italiana)-Limena; Lorenzetto E., Fondazione Malattie Rare "Mauro Baschirotto"-Costozza di Longare; Mancini B., ULSS 6 Vicenza-Ospedale di Vicenza-Vicenza; Marcante R., ULSS 4 Alto Vicentino-Ospedale di Santorso-Santorso; Montaldi A., ULSS 6 Vicenza-Ospedale di Vicenza-Vicenza; Passarotto M., Emolab-Conselve; Saccilotto D., ULSS 3-Ospedale di BassanoBassano del Grappa; Sanavio M., Emolab-Conselve; Veronesi A., ULSS 15 "Alta Padovana"-Padova; and Zocca E., Centro Medico Valentini/SELAB-Piombino Dese.

\section{DISCLOSURE}

The authors declare no conflict of interest.

\section{REFERENCES}

1. Rommens JM, Iannuzzi MC, Kerem B, et al. Identification of the cystic fibrosis gene: chromosome walking and jumping. Science 1989;245:1059-1065.

2. Watson MS, Cutting GR, Desnick RJ, et al. Cystic fibrosis population carrier screening: 2004 revision of American College of Medical Genetics mutation panel. Genet Med 2004;6:387-391.

3. American College of Obstetricians and Gynecologists Committee on Genetics. ACOG Committee Opinion No. 486: Update on carrier screening for cystic fibrosis. Obstet Gynecol 2011;117:1028-1031.
4. Castellani C, Macek M Jr, Cassiman JJ, et al. Benchmarks for cystic fibrosis carrier screening: a European consensus document. J Cyst Fibros 2010;9:165-178.

5. Strom CM, Crossley B, Buller-Buerkle A, et al. Cystic fibrosis testing 8 years on: lessons learned from carrier screening and sequencing analysis. Genet Med 2011;13:166-172.

6. Zlotogora J. Population programs for the detection of couples at risk for severe monogenic genetic diseases. Hum Genet 2009;126:247-253.

7. Massie J, Petrou V, Forbes R, et al. Population-based carrier screening for cystic fibrosis in Victoria: the first three years experience. Aust NZ J Obstet Gynaecol 2009;49:484-489.

8. Castellani C, Picci L, Tamanini A, Girardi P, Rizzotti P, Assael BM. Association between carrier screening and incidence of cystic fibrosis. JAMA 2009;302:2573-2579.

9. Cunningham S, Marshall T. Influence of five years of antenatal screening on the paediatric cystic fibrosis population in one region. Arch Dis Child 1998;78: 345-348.

10. Witt DWC, Goonewardena P, Louie E, Rosenfeld S. Cystic fibrosis prenatal screening of 103,600 individuals in an HMO: molecular/clinical outcomes and a dramatic reduction in CF incidence (abstract). American Society of Human Genetics (Proceedings of Annual Meeting), Philadelphia, 2008.

11. Sims EJ, Mugford M, Clark A, et al.; UK Cystic Fibrosis Database Steering Committee. Economic implications of newborn screening for cystic fibrosis: a cost of illness retrospective cohort study. Lancet 2007:369:1187-1195.

12. Lai HJ, Cheng Y, Farrell PM. The survival advantage of patients with cystic fibrosis diagnosed through neonatal screening: evidence from the United States Cystic Fibrosis Foundation registry data. J Pediatr 2005;147(3 suppl):S57-S63.

13. Farrell PM, Kosorok MR, Laxova A, et al. Nutritional benefits of neonatal screening for cystic fibrosis. Wisconsin Cystic Fibrosis Neonatal Screening Study Group. N Engl J Med 1997;337:963-969.

14. Southern KW, Munck A, Pollitt R, et al.; ECFS CF Neonatal Screening Working Group. A survey of newborn screening for cystic fibrosis in Europe. J Cyst Fibros 2007;6:57-65.

15. Castellani C, Southern KW, Brownlee K, et al. European best practice guidelines for cystic fibrosis neonatal screening. J Cyst Fibros 2009;8:153-173.

16. Kerem E, Conway S, Elborn S, Heijerman H; Consensus Committee. Standards of care for patients with cystic fibrosis: a European consensus. J Cyst Fibros 2005:4:7-26.

17. Smyth AR, Bell SC, Bojcin S, et al. European cystic fibrosis society standards of care: best practice guidelines. J Cyst Fibros. 2014 May;13 Suppl 1:S23-42. http://www. dx.doi.org/10.1016/j.jcf.2014.03.010.

18. Cystic Fibrosis Foundation. Borowitz D, Parad RB, Sharp JK, et al. Cystic Fibrosis Foundation practice guidelines for the management of infants with cystic fibrosis transmembrane conductance regulator-related metabolic syndrome during the first two years of life and beyond. J Pediatr 2009;155(6 suppl):S106-16.

19. Mayell SJ, Munck A, Craig JV, et al.; European Cystic Fibrosis Society Neonatal Screening Working Group. A European consensus for the evaluation and management of infants with an equivocal diagnosis following newborn screening for cystic fibrosis. J Cyst Fibros 2009;8:71-78.

20. Castellani $C$, Massie J. Newborn screening and carrier screening for cystic fibrosis: alternative or complementary? Eur Respir J 2014;43:20-23.

21. Sosnay PR, Siklosi KR, Van Goor F, et al. Defining the disease liability of variants in the cystic fibrosis transmembrane conductance regulator gene. Nat Genet 2013;45:1160-1167.

22. Efron B, Tibshirani R. Boostrap methods for standard errors, confidence intervals, and other measures of statistical accuracy. Stat Sci 1986;1:54-77.

23. Sontag MK, Wagener JS, Accurso F, Sagel SD. Consistent incidence of cystic fibrosis in a long-term newborn screen population. Ped Pulmonol 2008;(suppl 31): 272

24. Scotet $V$, Duguépéroux I, Saliou $P$, et al. Evidence for decline in the incidence of cystic fibrosis: a 35-year observational study in Brittany, France. Orphanet J Rare Dis 2012;7:14.

25. Scotet V, Assael BM, Duguépéroux I, et al. Time trends in birth incidence of cystic fibrosis in two European areas: data from newborn screening programs. J Pediatr 2008; 152:25-32.

26. Sims EJ, McCormick J, Mehta G, Mehta A; UK CF Database Steering Committee. Newborn screening for cystic fibrosis is associated with reduced treatment intensity. J Pediatr 2005;147:306-311.

27. Bombieri C, Claustres M, De Boeck K, et al. Recommendations for the classification of diseases as CFTR-related disorders. J Cyst Fibros 2011;10(suppl 2):S86-102. 